\title{
Article \\ Parks and Recreational Areas as Sinks of Plastic Debris in Urban Sites: The Case of Light-Density Microplastics in the City of Amsterdam, The Netherlands
}

\author{
Quirine M. Cohen ${ }^{1}$, Mae Glaese ${ }^{1,2}$, Ke Meng ${ }^{1}$, Violette Geissen ${ }^{1}$ and Esperanza Huerta-Lwanga ${ }^{1,3, *}$ \\ 1 Soil Physics and Land Management Degradation Group, Wageningen University \& Research, \\ 6708 PB Wageningen, The Netherlands; cohenquirine@gmail.com (Q.M.C.); l.glaese@ucr.nl (M.G.); \\ ke.meng@wur.nl (K.M.); violette.geissen@wur.nl (V.G.) \\ 2 Department of Environmental and Earth Science, University College Roosevelt, \\ 4331 CB Middelburg, The Netherlands \\ 3 Departamento de Agricultura, Sociedad y Ambiente, El Colegio de la Frontera Sur (ECOSUR), \\ Campeche 24500, Mexico \\ * Correspondence: esperanza.huertalwanga@wur.nl
}

check for

updates

Citation: Cohen, Q.M.; Glaese, M.;

Meng, K.; Geissen, V.; Huerta-Lwanga,

E. Parks and Recreational Areas as

Sinks of Plastic Debris in Urban Sites:

The Case of Light-Density

Microplastics in the City of

Amsterdam, The Netherlands.

Environments 2022, 9, 5. https://

doi.org/10.3390/environments9010005

Academic Editors: Teresa A.

P. Rocha-Santos and Joana C. Prata

Received: 30 November 2021

Accepted: 28 December 2021

Published: 30 December 2021

Publisher's Note: MDPI stays neutral with regard to jurisdictional claims in published maps and institutional affiliations.

Copyright: () 2021 by the authors. Licensee MDPI, Basel, Switzerland. This article is an open access article distributed under the terms and conditions of the Creative Commons Attribution (CC BY) license (https:// creativecommons.org/licenses/by/ $4.0 /)$.

\begin{abstract}
Soils of parks and recreational areas are potential sinks of microplastics because they are under multifunctional use. The aims of this research were to quantify and determine the types and abundance of light-density microplastics in one of the most cosmopolitan cities of the world: Amsterdam, The Netherlands. Therefore, potential differences between the city districts were explored through the assessment of light-density microplastics' concentrations in soils together with the soil properties. Microplastics were extracted from 74 soil samples. Predictions of microplastic concentrations and soil characteristics were made for the entire city by using ordinary kriging; $97 \%$ of the samples contained microplastic particles (MPPs), and on average, there were $4825.31 \pm 6513.85 \mathrm{MPP} / \mathrm{kg}$ soil. A total of 21 hotspot samples were identified, and all of them contained LDPE, which represented $40.82 \%$ of the plastic types, in addition to $35.06 \%$ PAC and $15.58 \%$ natural polyamide. Other types of plastics were PP $(0.19 \%)$, PS (1.30\%), bioplastic $(0.19 \%)$, PA (0.37\%), PU (0.56), PVC $(0.19 \%)$, and unidentified plastics $(0.19 \%)$. There were no significant differences in MPP concentration between city districts. Our results showed that MPPs are abundant in urban soils, which represents a high risk for soil life. Further studies are required for identifying the sources of this pollution.
\end{abstract}

Keywords: microplastics; urban areas; parks

\section{Introduction}

It is predicted that the current worldwide production of plastic will double in the coming 20 years, extending the post-consumer waste [1]. When not collected and processed correctly, it is evident that plastic debris will end up in the environment [2]. Microplastic pollution has been researched extensively in the marine environment [3] and to some degree in the terrestrial environment [4-6]. However, research on microplastic pollution in an urban environment has been lacking [7]. This is remarkable, since cities can contain plastic debris in their soil itself, and they be a source for plastic debris outside the urban areas $[6,8]$.

Since most plastic litter comes from land, it is highly likely that these plastics have first interacted with the terrestrial ecosystem [9]. Microplastics are small particles of $<5 \mathrm{~mm}$ that are insoluble in water, non-degradable, and have chemical properties that influence their availability to organisms [10]. Studies have shown that microplastic pollution is related to its degradation rate, which is generally slow or does not even occur [4,11]. These particles can be transported through the soil both horizontally and vertically through anthropogenic activities or naturally by either leaching or earthworms [4,12]. Moreover, microplastics 
can increase mortality rates and decrease reproduction rates, in addition to reducing the growth of earthworms [13].

There are multiple ways that plastic debris can end up in an urban environment. Agricultural practices are suggested to be the main contributor and could be a source of plastic debris in urban soils through atmospheric transportation $[6,14]$. Other sources include release from (1) transportation, which can occur from damaged vehicles or road channelizing devices [7], (2) littering by individuals after using plastic materials [15], (3) deposition after plastic products [16] or synthetic fibres from clothes or houses leach into the atmospheric compartment [17], and, finally, (4) plastic debris entering the terrestrial environment after tourism-related land use. Amsterdam is famous for its eight canals within the city centre, which are part of the UNESCO World Heritage [18], making it a popular tourist destination. Moreover, tourism is increasing each year due to Amsterdam's open-minded reputation and marketing efforts from the city itself, which leads to more littering [19]. Another tourism-related land use is from events, such as festivals. Festivals are typically large public events that last for a short time frame [20]. In The Netherlands, 50 million $\mathrm{kg}$ of plastic garbage is produced by all festivals each year [21]. Since Amsterdam hosts most of the festivals in The Netherlands (192 in 2018) [21], this could be a likely source.

Currently, 862,987 people are living in Amsterdam, the capital of The Netherlands [22]. In 2018, $3.5 \mathrm{~kg}$ plastic garbage was produced per person [23]. Amsterdam lies next to the North Sea and is surrounded by nature reserves that are part of the UNESCO World Heritage [24]. Due to its (culturally valued) geographical location, plastic pollution can have devastating effects on the environment.

Even though the terrestrial environment can act as a permanent sink of microplastics, research has been still lacking [7]. Some studies analysed microplastics in urban dust [7,25] or urban stormwater retention ponds [26] and scare are those studies developed in urban soils [27]. Therefore, this study aims to (1) quantify light-density MPPs in parks and recreational areas in Amsterdam, (2) analyse the size distribution of MPPs, (3) investigate whether there were differences in MPP concentration and size distribution between parks and recreational areas, neighbourhoods, or city districts in Amsterdam, (4) identify plastic types from hotspot samples, (5) evaluate the chemical and physical soil characteristics and their relationships with MPPs, and, finally, (6) predict MPP concentrations and chemical and physical soil characteristics for the entire city through a spatial distribution approach.

\section{Materials and Methods}

\subsection{Study Area and Sample Collection}

Soil samples were taken from 10 parks, 12 recreational places, and 1 city forest in the urban area of Amsterdam, the capital of The Netherlands (Figure 1). Those soils are known as peat soils [28]. Amsterdam is divided into seven city districts: Centrum, Nieuw-West, Noord, Oost, West, Zuid, and Zuidoost.

A total of $64,300 \mathrm{~g}$ of soil samples were collected within a regular grid (with a distance of $330 \mathrm{~m}$ between points), and 10 additional samples were randomly taken within $30 \mathrm{~m}$ of the pre-set locations. In total, 74 samples were taken from the top $30 \mathrm{~cm}$ soil layer using a cylindrical auger (diameter $=5 \mathrm{~cm}$ ) made from steel to prevent contamination. The procedure of $[29,30]$ was followed, since plastics accumulate in the upper $25 / 30 \mathrm{~cm}$ of arable soils, where $95 \%$ of microplastics are present. Each sample was transported within a paper bag $(16 \times 10 \times 35 \mathrm{~cm})$ to prevent contamination, and was then stored in a refrigerator at $5{ }^{\circ} \mathrm{C}$ until further laboratory analyses. 


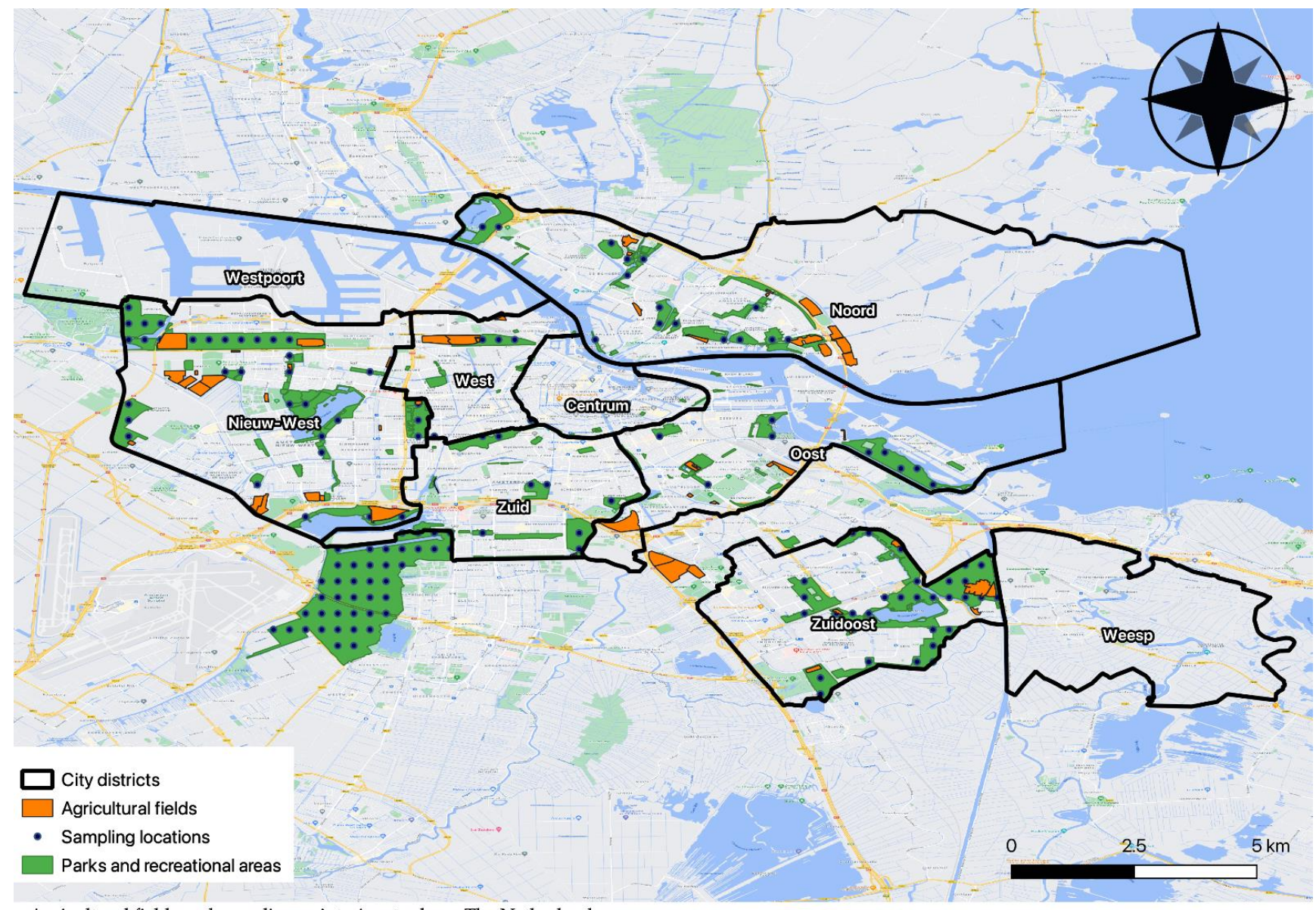

Agricultural fields and sampling points Amsterdam, The Netherlands

Figure 1. Sampling points in parks and recreational areas in Amsterdam, The Netherlands.

\subsection{Microplastic Extraction}

Microplastic extraction was based on the method proposed by Zhang [29], modified from [31] (in short, a flotation method based on density difference). First, all samples were air-dried in an oven at $40{ }^{\circ} \mathrm{C}$ for $24 \mathrm{~h}$. Samples were gently pressed through a $2 \mathrm{~mm}$ sieve that was made from steel to prevent plastic contamination, weighted to $5.00 \pm 0.01 \mathrm{~g}$, and put into $50 \mathrm{~mL}$ glass tubes to prevent contamination.

A total of $40 \mathrm{~mL}$ of distilled water was added to the tubes and mixed in a Gerhardt Laboshake shake at $120 \mathrm{rpm}$ for 30 to $40 \mathrm{~min}$ instead of $2 \mathrm{~h}$, as proposed by Zhang [29] because the soil samples had less organic matter [32,33] and no hard aggregates. Second, samples were centrifuged at $3000 \mathrm{rpm}$ for ten minutes. After centrifuging, the supernatant was filtered using Whatmann 91 filters with a pore size of $<7 \mathrm{~mm}$, which were made from paper to prevent contamination. Samples were topped up until they reached $50 \mathrm{~mL}$ again, and the process was repeated three times. Between iterations of filtering, all samples were covered with paper cloth to prevent contamination.

Afterwards, the samples were put into an ultrasound machine for two hours to break up any remaining aggregates. The samples were left overnight, covered with paper cloth to prevent contamination, and filtered. The filters were then dried in the oven at $60{ }^{\circ} \mathrm{C}$ for $3 \mathrm{~h}$. After drying, the filters were folded shut to prevent contamination and were stored in a dark cupboard until the analyses.

\subsection{Microplastic Constatation}

To recognise microplastics, filter residue was brushed onto a glass plate using a finest red sable (da Vinci) paintbrush (number 5) with weasel hairs to prevent contamination. During constatation, the researcher wore mainly cotton clothes and a cotton coat. Two 
pictures were taken using a ZEISS Stemi 508 microscope (1:8 zoom) before and after heating for $30 \mathrm{~s}$ at $140-150{ }^{\circ} \mathrm{C}$. Microplastics were selected in Photoshop by using changes in shape, colour, or transparency after heating (Figure S1, according to Zhang [29]). Each selection was analysed for the plastic count and size using ImageJ.

\subsection{Microplastic Identification}

To identify the types of microplastics, a random subgroup from the sampling locations with the highest microplastic concentrations in the soils was assessed. It was decided to analyse a subgroup, since the identification method was highly time consuming. Seven sampling locations were analysed in triplicate; the locations were: 'Westerpark', 'Gerbrandypark', 'Flevopark', 'Nelson Mandelapark', and three from the 'Amsterdamse Bos', hereafter called Amsterdamse Bos 1, Amsterdamse Bos 2, and Amsterdamse Bos 3. Plastic was extracted by following the method explained in Section 2.2. After extraction, the 21 samples were identified using a Laser Direct Infrared Chemical Imaging System (8700 LDIR). After identification, a correlation matrix was made for all of the particles. When the correlation of the absorbance spectra of the plastic type in the sample and absorbance spectra of the plastic type from the LDIR library was above 0.85 , the plastic type was considered a match.

\subsection{Soil Characterization by Using Organic Carbon Content, Moisture Content, and $p H$}

Soils were characterized by using organic matter content, moisture, and $\mathrm{pH}$; the methods' descriptions are present in the Supplementary Materials.

\subsection{Data Analysis}

A Shapiro-Wilk test was performed to test for data normality, and it showed that the data were not normally distributed $(p<0.05)$. To determine if there were any statistical differences among parks and recreational areas, a Kruskal-Wallis test was performed. Afterwards, potential differences were identified using a post-hoc Mann-Whitney U test. To differentiate between the sizes of the particles, the particles were divided into four size groups: A: >1 mm, B: 0.50-1 mm, C: 0.25-0.50 mm, and D: $<0.25 \mathrm{~mm}$. Correlations between microplastic concentration, OCC, $\mathrm{MC}$, and $\mathrm{pH}$ were determined using Spearman tests. All tests were performed in RStudio (Version 1.2.5) using a significance level of $p<0.05$.

\subsection{Geostatistical Analysis}

Geostatistics were used to examine the spatial distribution structures of MPP concentration, organic carbon content, moisture content, and $\mathrm{pH}$ in soils. The main tool for the analyses was the semi-variance function; the semi-variogram (Figures S2-S9) value was calculated using Equation (1).

$$
\gamma(h)=1 / 2 N(h) \sum_{n i=1}^{N(h)}[Z(x i)-Z(x i+h)]^{2}
$$

$\gamma(h)$, or the semi-variance value, is half of the expected squared difference between the value of $Z$ at two locations separated by the distance interval $h$. The spatial structure was best fit by the spherical variogram model. The parameters used are:

- $\quad$ nugget variance: the random variation of the short distance.

- $\quad$ sill: the maximum value of the semi-variogram.

- $\quad$ range: the separation distance at probable spatial dependence.

The variogram was then fitted in R-studio (Version 1.2.5). The nugget-to-sill ratios and variograms can be found in the Supplementary Materials.

\section{Results}

\subsection{Microplastic Particles in Soils by City District}

Microplastic particles were found in $97 \%$ of the analysed samples. Most particles were found in 'Oost', and the lowest concentrations were found in 'Zuid Oost': $5996 \pm 10,658$ 
and $1198 \pm 2879 \mathrm{MPP} \mathrm{kg}-1$, respectively (Tables S1 and S2). There were no significant differences between city districts $(p<0.05$, Figure 2$)$. Outliers were present in 'Amsterdamse Bos' and 'Zuid Oost'. The hotspot samples had around $78.7 \pm 12$ microplastics per gram of soil (these particles were identified in $380 \pm 95$ extracted and studied particles per gram of soil in the assessment with the LDIR).

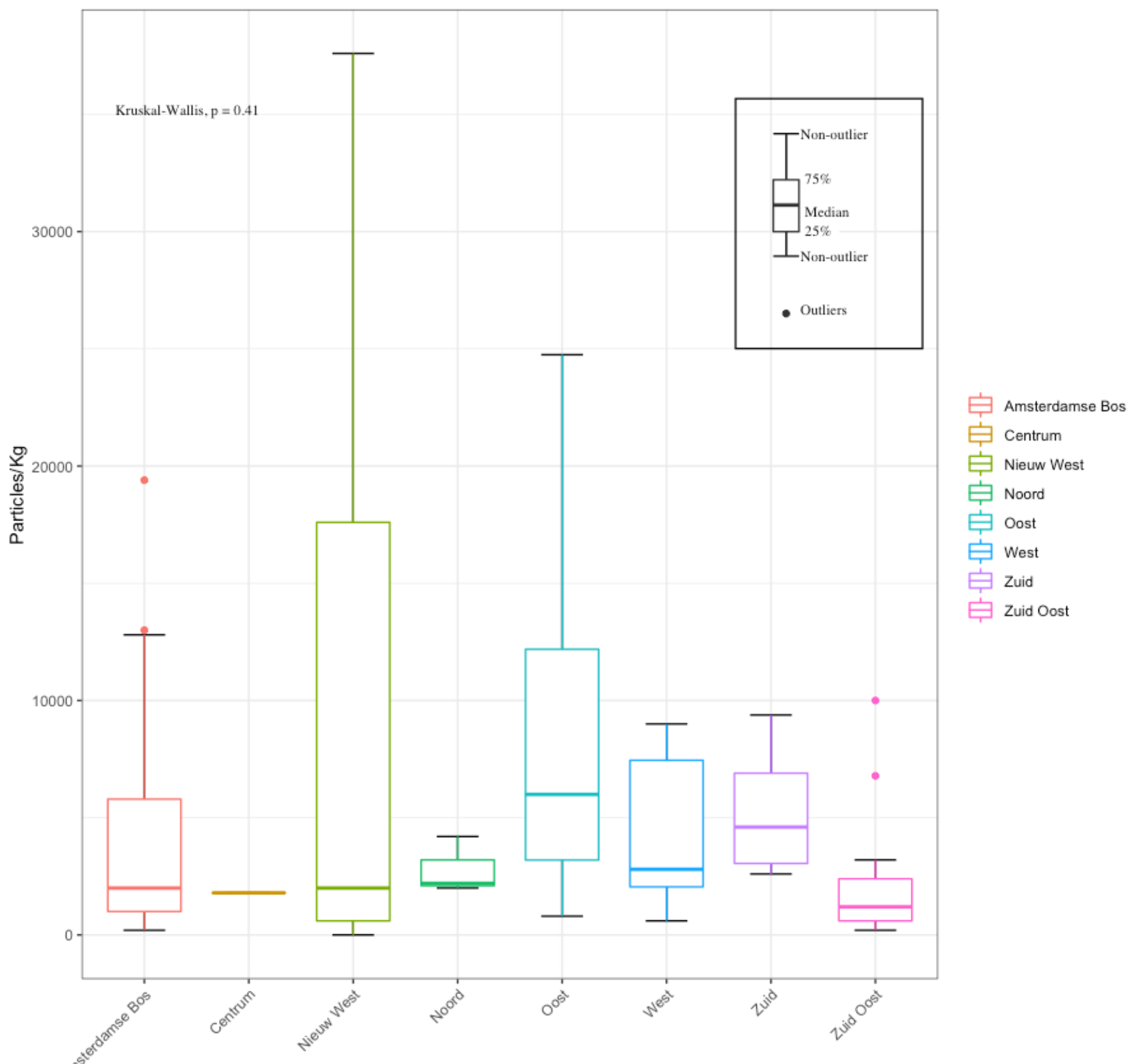

City districts

Figure 2. Visualization of microplastic concentrations $\left(\mathrm{MPP} \mathrm{Kg}^{-1}\right)$ in soils from parks and recreational areas $(\mathrm{n}=74)$ by city district in Amsterdam.

\subsection{Microplastic Size Distribution by City District}

The size distribution was analysed by city district (Figure 3). The highest significant median was found in 'Oost' $(0.37 \mathrm{~mm})$, and the lowest was found in 'Noord' $(0.19 \mathrm{~mm})$. The largest diameter was found in 'Oost' $(0.40 \mathrm{~mm})$. All city districts showed outliers. The Kruskal-Wallis test showed significant differences between city districts $(p<0.05)$. 


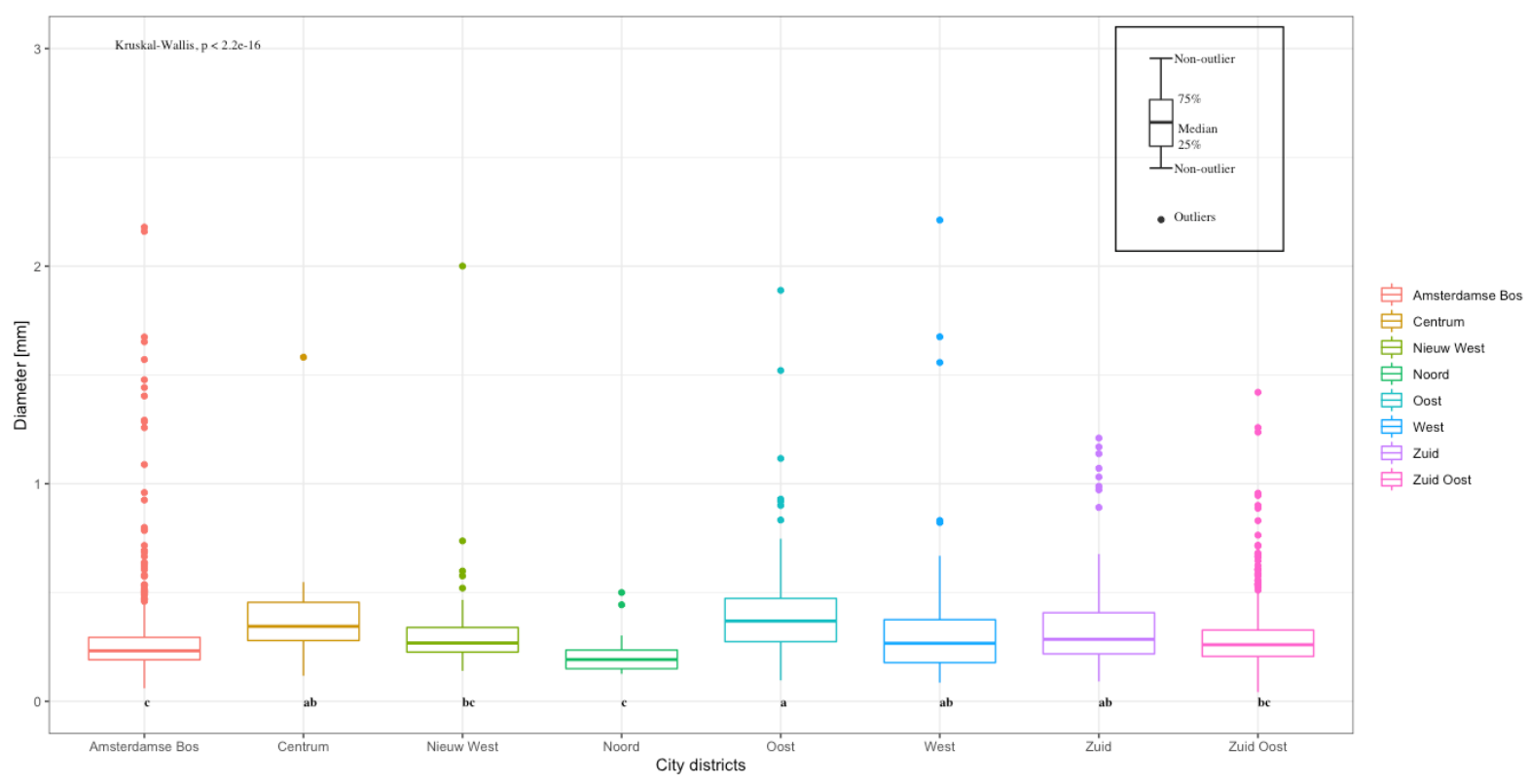

Figure 3. Size distribution (diameter in $\mathrm{mm}$ ) of microplastic particles $(\mathrm{n}=1748)$ in soils from parks and recreational areas $(n=74)$, which were analysed by city district in Amsterdam. Significant differences between city districts $(p<0.05)$ are indicated by lowercase letters $(a>b>c)$.

\subsection{Microplastic Types}

Each sample contained low-density polyethylene (LDPE) $(40.82 \%)$, natural polyamide $(15.58 \%)$, pro-oxidant-additive-containing (PAC) plastics $(36.36 \%)$, polypropylene (PP, $0.19 \%)$, polystyrene (PS, $1.30 \%)$, bioplastic $(0.19 \%)$, polyamide (PA, $0.37 \%)$, polyurethane (PU, $0.56 \%$ ), polyvinyl chloride (PVC, $0.19 \%$ ), and unidentified plastics (3.71\%). The plastic type with the highest concentration was LDPE, which was found in the Amsterdamse Bos 3 with 8800 particles $/ \mathrm{kg}$ soil (Figure 4). The shapes and colours of the microplastics were not characterised.

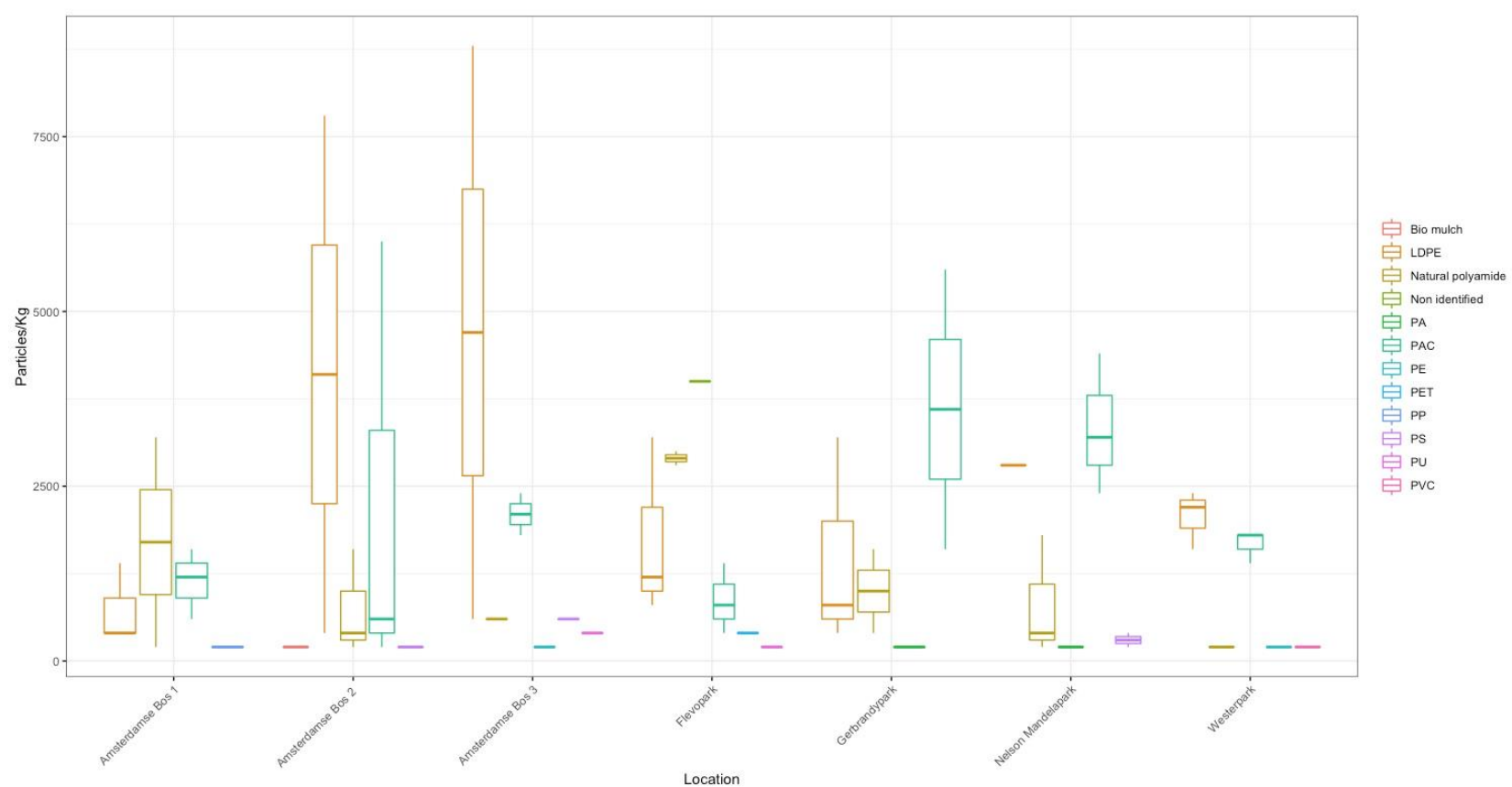

Figure 4. Plastic types in soils from parks and recreational areas that were analysed by city district in Amsterdam. 
3.4. Soil Microplastics, Organic Carbon Content, Moisture Content, and $p H$ Prediction in the Soils of Amsterdam

The microplastic concentration was predicted for the entire city using a spherical model in the semi-variogram (Supplementary data). Figure 5 shows that the soils, on average, contained $5000 \mathrm{MPP} \mathrm{kg}{ }^{-1}$ and were moderately spatially dependent, which could be concluded from the nugget-to-sill ratio (Supplementary data). A hotspot was observed in the western part of the city.

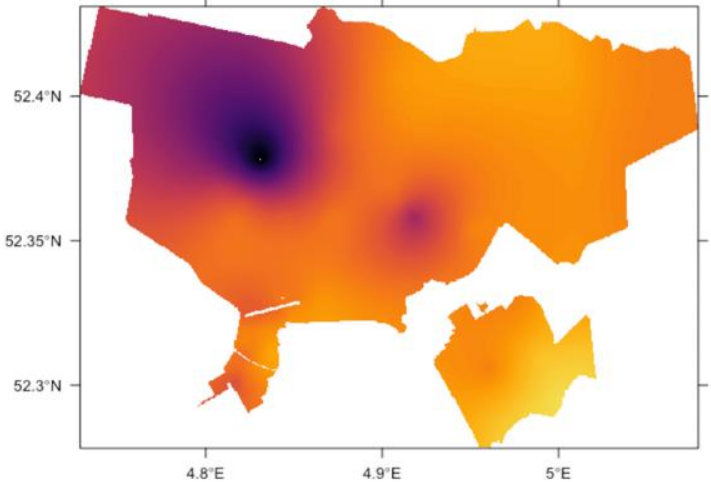

(a) Microplastics $\mathrm{Kg}^{-1}$ soil in Amsterdam

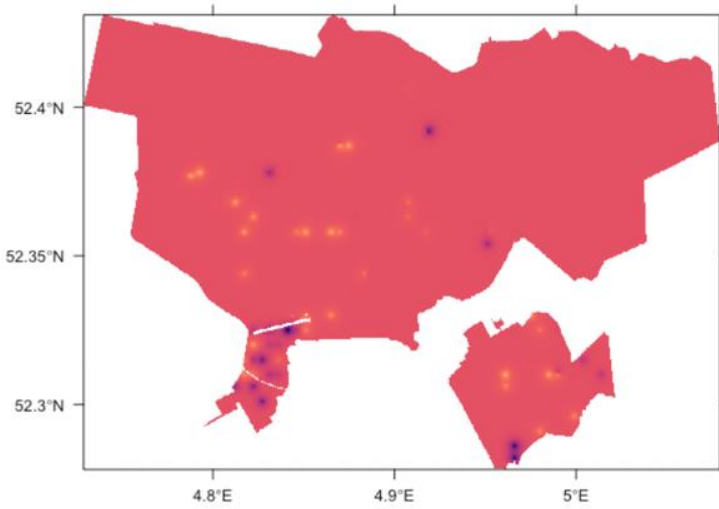

(c) Moisture content [\%] in Amsterdam
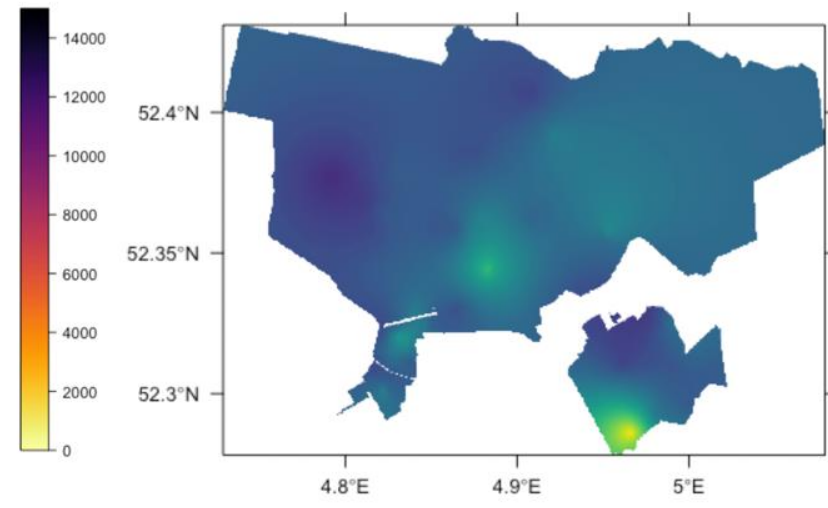

(b) Organic carbon content [\%] in Amsterdam
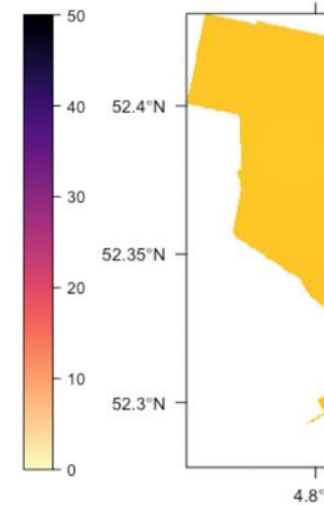

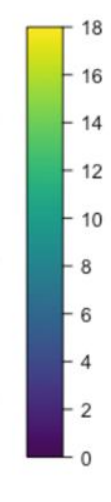

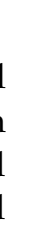


was observed. The semi-variogram of the moisture content, which was plotted using a spherical model, showed that the data were moderately spatially dependent.

The highest median $\mathrm{pH}$ was found in the city district 'Centrum' (7.28). The lowest median $\mathrm{pH}$ was found in 'Noord' (6.89). Outliers were found in 'Amsterdamse Bos', 'Nieuw West', 'West', and 'Zuid Oost'. The $\mathrm{pH}$ showed no significant differences between city districts. The average $\mathrm{pH}$ was 6.96 and did not change much by city district (Figure $5 \mathrm{~d}$ ). The semi-variogram was plotted using a spherical model and showed that the data were moderately spatially dependent. The correlation was slightly positive, but insignificant.

\section{Discussion}

\subsection{Microplastic Concentration in City Districts}

It can be stated that MPPs are abundant in the soils of Amsterdam. In this study, $97 \%$ of the samples contained MPPs, with a mean of $4825.31 \pm 6513.85 \mathrm{MPP} / \mathrm{kg}$ soil. The study by Huerta Lwanga [34] was the most similar in terms of methodology, where soil samples were analysed for microplastics in home gardens with a similar extraction method. In that research, $870 \pm 1900 \mathrm{MPPs} / \mathrm{kg}$ were found in soil. These results are much lower than those calculated in this study. It is known that a denser population results in more plastic waste and litter [7]. Unfortunately, there are no exact data available on the amount of litter in Amsterdam. Nevertheless, it is estimated that the amount of litter in The Netherlands lies between 50 and 275 million $\mathrm{kg}$ per year. This includes data on litter that is cleaned by street cleaners [35]. Moreover, it is estimated that in Europe, annually, between 1270 and 2130 tonnes of microplastics/million inhabitants are unloaded in urban environments [6]. In Amsterdam, this would mean that each year, between 1043 and 1750 tonnes of microplastics are released into the environment. Other potential sources of microplastics in urban environments are tire abrasion, construction, atmospheric dispersion, and washing of synthetic clothing [7]. Generally, quantitative research on potential sources of microplastics in the environment is lacking. Studies are restricted by the complex sources, incomplete data on transport and fate in the general environment, and high geographical variability [36].

The highest microplastic concentration was found in 'Nieuw-West', and the lowest was found in 'Zuidoost'. The highest median, however, was found in 'Oost' (5996 \pm 10,658 $\mathrm{MPP} / \mathrm{kg}$ ). Corresponding to the results in the parks and neighbourhoods, 'Oost' is crossed by a railway and a highway. This could explain the higher concentration of MPP $/ \mathrm{kg}$ in the soil. Nevertheless, the differences between city districts were insignificant; it is possible that this was due to the low number of sampling locations per city district.

As mentioned before, it was proposed that a higher population density would result in a higher MPP $/ \mathrm{kg}$ concentration. This does not correspond to our data, as 'Oost' does not have the highest number of residents.

\subsection{Size Distribution of Microplastic Particles in Amsterdam}

Most particles (on average, $47 \pm 22 \%$ ) had a diameter $<0.25 \mathrm{~mm}$. Plastic particles become so small due to several factors, such as embrittlement, photo-oxidation, abrasion, or fragmentation by UV light [37]. The distribution of the diameter of each MPP was categorized per city district. The largest median was discovered in 'Centrum' $(0.48 \mathrm{~mm})$. The environmental risk that this represents is related to the ingestion of MPPs by soil fauna. According to Huerta Lwanga [38], earthworms are able to bioturbate particles up to a size of $0.50-1 \mathrm{~mm}$; nevertheless, it is mostly particles smaller than $0.25 \mathrm{~mm}$ that are found in their guts. When microplastics end up in earthworms' guts, they can result in weight loss, lower growth rates, and even mortality, thus decreasing soil quality [38].

Furthermore, when burrows created by earthworms become denser, organic matter concentrates in the burrow walls, which, in turn, can increase the inclination toward sorption of contaminants [38]. Moreover, the bioturbation of microplastics in earthworms can result in accumulation in the food chain, thus posing a threat for human health. Microplastics haven been found in several types of terrestrial animals [39], such as chickens [34]. 
Finally, it is suggested that terrestrial organisms and soil microbial communities may advance the degradation of plastics into microplastics or even nanoplastics. This can, in turn, stimulate the soil as a long-term sink of micro- and nanoplastics [14].

\subsection{Microplastic Types}

The types of microplastics were determined in seven sampling points from the areas with the highest concentrations of MPPs in soils. Each sample contained LDPE, natural polyamide, and PAC. LDPE is mostly related to packaging and is frequently used to produce film. Natural polyamide is a form of bioplastic, which is plastic derived from biomass and is most often produced by transforming cellulose into products that have thermoplastic properties, such as films and fibres [40]. Other natural polymers that can be used to produce natural polyamide are starch, polyhydroxyalkaboates (PHAs), or lignin [40]. PAC plastics are conventional fossil-based polymers containing additives to enhance polymer degradation when exposed to light and/or heat [41]. In this research, PAC plastic is LDPE with additives, which is often produced in the market as oxodegradable plastic bags or other single-use plastics. PE, PP, PVC, PET, PS, and PA are all considered thermoplastics, which melt when heated and harden when cooled [42]. PP and PE are mostly used in packaging, but are used in all sectors of primary plastic production worldwide [42]. PVC is mostly used in the construction sector, and is often used for pipes, hoses, and window and door frames [42], whereas PET is almost only used in packaging, mostly for bottles [43]. PUR is an example of a thermoset and is mostly used for foam products, such as insulation material. PS is used for food packaging, plastic cups, and cutlery [43]. It is noticeable that most of the recovered plastic types are used in either the packaging or construction industry. This coincides with findings by Geyer [42], where it was found that in 2017, the global primary plastic production was mostly made up by packaging (36\%), followed by construction $(16 \%)$. This could mean that most of the plastics recovered in the parks and recreational areas are related to littering or construction work.

\subsection{Microplastics and Soil Organic Matter, $p H$, and Moisture}

It was a challenge to try to understand if microplastics could be related to soil properties. The idea arose from trying to infer that soils that are rich in organic matter are those that have been under a continuous supply of fertilisers or composts (composts are also known to vehicles of microplastics [44]). Consequently, the following hypothesis can be addressed: In soils where compost was added intensively, will there also be high concentrations of microplastics? We cannot know, as in the present study, it was not possible to elucidate this from the soil data. It is necessary to study the land use and the constant application of composts, which was outside of the scope of this study. Further studies are needed to understand the spatial distribution of microplastics and its relation with soils that are rich in organic matter in the soils of parks and recreational areas in Amsterdam.

\section{Conclusions}

It can be concluded that microplastic particles are abundant in the soils of Amsterdam. Although there were no significant differences between city districts, understanding the differences could aid in policy making in order to minimize the negative environmental effects of microplastic pollution. A total of $53 \%$ of all particles were smaller than $0.25 \mathrm{~mm}$, thus posing a threat to soil quality. Most plastic types that were recovered were related to the packaging and construction sector, indicating that the main sources of microplastics in the soil could be from littering and construction work. The relationship of microplastics with several soil properties is still insufficiently understood, but it is clear that the spatial distribution is determined by anthropogenic factors.

Supplementary Materials: The following are available online at https: / www.mdpi.com/article/ 10.3390/environments9010005/s1, Figure S1: Pictures of plastic particles after and before heating. Figure S2: Variogram of MPP/Kg in Amsterdam, The Netherlands. Figure S3: Fitted variogram 
of $\mathrm{MPP} / \mathrm{Kg}$ in Amsterdam, The Netherlands. Figure S4: Variogram organic carbon content in Amsterdam, The Netherlands (before fitting). Figure S5: Fitted variogram organic carbon content in Amsterdam, The Netherlands. Figure S6: Variogram moisture content in Amsterdam, The Netherlands (before fitting). Figure S7: Fitted variogram of moisture content in Amsterdam, The Netherlands. Figure S8: Variogram of $\mathrm{pH}$ in Amsterdam, The Netherlands (before fitting). Figure S9: Fitted variogram of $\mathrm{pH}$ in Amsterdam, The Netherlands. Table S1: Statistical data of microplastic particles per $\mathrm{kg}$ per city district in Amsterdam. No significant differences between city districts were observed after a Kruskal-Wallis test. Table S2: Microplastic particles [MPP/Kg] per park or recreational area in Amsterdam, The Netherlands.

Author Contributions: Conceptualization, E.H.-L. and Q.M.C.; methodology, Q.M.C., K.M. and M.G.; validation, all authors participated; formal analysis, Q.M.C. and M.G.; investigation, Q.M.C., M.G. and E.H.-L.; resources, E.H.-L. and V.G.; data curation, Q.M.C.; writing-original draft preparation, Q.M.C. and E.H.-L.; writing-review and editing, Q.M.C., E.H.-L. and V.G.; visualization, Q.M.C. and E.H.-L.; supervision, E.H.-L.; project administration, E.H.-L.; funding acquisition, V.G. All authors have read and agreed to the published version of the manuscript.

Funding: This research received no external funding.

Acknowledgments: We would like to acknowledge Ir. Gerard Heuvelink and Cynthia van Leeuwen for their advice on geostatistics.

Conflicts of Interest: The authors declare no conflict of interest.

\section{References}

1. Lebreton, L.; Andrady, A. Future scenarios of global plastic waste generation and disposal. Palgrave Commun. 2019, 5, 1-11. [CrossRef]

2. Rillig, M.C. Microplastic in terrestrial ecosystems and the soil? Environ. Sci. Technol. 2012, 46, 6453-6454. [CrossRef]

3. Foley, C.J.; Feiner, Z.S.; Malinich, T.D.; Höök, T.O. A meta-analysis of the effects of exposure to microplastics on fish and aquatic invertebrates. Sci. Total Environ. 2018, 631-632, 550-559. [CrossRef]

4. Bläsing, M.; Amelung, W. Plastics in soil: Analytical methods and possible sources. Sci. Total Environ. 2018, 612, 422-435. [CrossRef] [PubMed]

5. Fuller, S.; Gautam, A. A Procedure for Measuring Microplastics using Pressurized Fluid Extraction. Environ. Sci. Technol. 2016, 50, 5774-5780. [CrossRef] [PubMed]

6. Nizzetto, L.; Futter, M.; Langaas, S. Are Agricultural Soils Dumps for Microplastics of Urban Origin? Environ. Sci. Technol. 2016, 50, 10777-10779. [CrossRef] [PubMed]

7. Dehghani, S.; Moore, F.; Akhbarizadeh, R. Microplastic pollution in deposited urban dust, Tehran metropolis, Iran. Environ. Sci. Pollut. Res. 2017, 24, 20360-20371. [CrossRef]

8. Chae, Y.; An, Y.J. Current research trends on plastic pollution and ecological impacts on the soil ecosystem: A review. Environ. Pollut. 2018, 240, 387-395. [CrossRef] [PubMed]

9. Machado, A.A.d.S.; Kloas, W.; Zarfl, C.; Hempel, S.; Rillig, M.C. Microplastics as an emerging threat to terrestrial ecosystems. Glob. Chang. Biol. 2018, 24, 1405-1416. [CrossRef] [PubMed]

10. Zhang, S.; Yang, X.; Gertsen, H.; Peters, P.; Salánki, T.; Geissen, V. A simple method for the extraction and identification of light density microplastics from soil. Sci. Total Environ. 2018, 616-617, 1056-1065. [CrossRef]

11. Restrepo-Flórez, J.M.; Bassi, A.; Thompson, M.R. Microbial degradation and deterioration of polyethylene-A review. Int. Biodeterior. Biodegrad. 2014, 88, 83-90. [CrossRef]

12. Rillig, M.C.; Ziersch, L.; Hempel, S. Microplastic transport in soil by earthworms. Sci. Rep. 2017, 7, 1-6.

13. Huerta Lwanga, E.; Gertsen, H.; Gooren, H.; Peters, P.; Salánki, T.; Ploeg, M.v.d.; Besseling, E.; Koelmans, A.A.; Geissen, V. Microplastics in the Terrestrial Ecosystem: Implications for Lumbricus terrestris (Oligochaeta, Lumbricidae). Environ. Sci. Technol. 2016, 50, 2685-2691. [CrossRef] [PubMed]

14. Hurley, R.R.; Nizzetto, L. Fate and occurence of micro (nano) plastics in soils: Knowledge gaps and possible risks. Curr. Opin. Environ. Sci. Health 2018, 1, 6-11. [CrossRef]

15. Eriksen, M.; Mason, S.; Wilson, S.; Box, C.; Zellers, A.; Edwards, W.; Farley, H.; Amato, S. Microplastic pollution in the surface waters of the Laurentian Great Lakes. Mar. Pollut. Bull. 2013, 77, 177-182. [CrossRef]

16. Teil, M.J.; Blanchard, M.; Chevreuil, M. Atmospheric fate of phthalate esters in an urban area (Paris-France). Sci. Total Environ. 2006, 354, 212-223. [CrossRef] [PubMed]

17. Dris, R.; Gasperi, J.; Saad, M.; Mirande, C.; Tassin, B. Synthetic fibers in atmospheric fallout: A source of microplastics in the environment? Mar. Pollut. Bull. 2016, 104, 290-293. [CrossRef]

18. Zukin, S. The social production of urban cultural heritage: Identity and ecosystem on an Amsterdam shopping street. City Cult. Soc. 2012, 3, 281-291. [CrossRef] 
19. Gerritsma, R. Overcrowded Amsterdam: Striving for a balance between trade, tolerance and tourism. In Overtourism: Excesses, Discontents and Measures in Travel and Tourism; Cheer and Marina Novelli: Wallingford, UK, 2019; pp. $125-147$.

20. Essonanawe, M.; Fruergaard, T.; Pivnenko, K.; Edjabou, M.; Boldrin, A.; Astrup, T. Challenge of Material Recycling at Large Public Events. In Proceedings of the 16th International Waste Management and Landfill Symposium, Sardinia, Italy, $2-7$ October 2017.

21. Gans, W.D. Handboek voor een Afvalvrij Festival. 2017. Available online: https://www.metabolic.nl/publications/handboekvoor-een-afvalvrij-festival/ (accessed on 27 December 2021).

22. Bevolkingsprognoses Amsterdam. Onderzoek, Informatie en Statistiek. Available online: https://data.amsterdam.nl/datasets/ Y1Uw9Zh-qZyZAQ/bevolkingsprognoses-amsterdam/ (accessed on 30 April 2020).

23. Afvalverwerking in Amsterdam. Gemeente Amsterdam, Onderzoek, Informatie en Statistiek. Available online: https://data. amsterdam.nl/datasets / zIe2GGF-IVNxAQ/afvalverwerking-in-amsterdam/ (accessed on 30 April 2020).

24. Folmer, A.; Revier, H.; Cupido, T. Sustainable tourism development and the world heritage status of the Wadden Sea: The case of Terschelling. Res. Hosp. Manag. 2016, 6, 45-50. [CrossRef]

25. Yukioka, S.; Tanaka, S.; Nabetani, Y.; Suzuki, Y.; Ushijima, T.; Fujii, S.; Takada, H.; Tran, Q.v.; Singh, S. Occurrence and characteristics of microplastics in surface road dust in Kusatsu (Japan), Da Nang (Vietnam), and Kathmandu (Nepal). Environ. Pollut. 2020, 256, 113447. [CrossRef]

26. Liu, F.; Olesen, K.B.; Borregaard, A.R.; Vollertsen, J. Microplastics in urban and highway stormwater retention ponds. Sci. Total Environ. 2019, 671, 992-1000. [CrossRef]

27. Zhou, Y.; Liu, X.; Wang, J. Characterization of microplastics and the association of heavy metals with microplastics in suburban soil of central China. Sci. Total Environ. 2019, 694, 133798. [CrossRef]

28. Gans, W.D. De Bodem onder Amsterdam: Een Geologische Stadswandeling; Utrecht TNO Geologische Dienst Nederland: Utrecht, The Netherlands, 2011.

29. Zhang, S.; Wang, J.; Liu, X.; Qu, F.; Wang, X.; Wang, X.; Li, Y.; Sun, Y. Microplastics in the environment: A review of analytical methods, distribution, and biological effects. TrAC Trends Anal. Chem. 2019, 111, 62-72. [CrossRef]

30. Hanvey, J.S.; Lewis, P.J.; Lavers, J.L.; Crosbie, N.D.; Pozo, K.; Clarke, B.O. A review of analytical techniques for quantifying microplastics in sediments. Anal. Methods 2017, 9, 1369-1383. [CrossRef]

31. Berg, P.v.d.; Huerta-Lwanga, E.; Corradini, F.; Geissen, V. Sewage sludge application as a vehicle for microplastics in eastern Spanish agricultural soils. Environ. Pollut. 2020, 261, 114198. [CrossRef] [PubMed]

32. Margesin, R.; Schinner, F. Monitoring and Assessing Soil Bioremediation; Springer: Berlin/Heidelberg, Germany, $2005 ;$ Volume 5.

33. Nelson, D.W. Chapter 34 Total Carbon, Organic Carbon, and Organic Matter. In Methods of Soil Analysis: Part 3 Chemical Methods; Wiley: Madison, WI, USA, 1996; p. 53711.

34. Huerta Lwanga, E.; Vega, J.M.; Quej, V.K.; Chi, J.d.l.A. Field evidence for transfer of plastic debris along a terrestrial food chain. Sci. Rep. 2017, 7, 1-7. [CrossRef] [PubMed]

35. Waart, S.d.; Jong, W.d.; Tijs, M. Zwerfafval; Milieu Center: Sacramento, CA, USA, 2015.

36. Duis, K.; Coors, A. Microplastics in the aquatic and terrestrial environment: Sources (with a specific focus on personal care products), fate and effects. Environ. Sci. Eur. 2016, 28, 1-25. [CrossRef] [PubMed]

37. Huerta Lwanga, E.; Gertsen, H.; Gooren, H.; Peters, P.; Salánki, T. Incorporation of microplastics from litter into burrows of Lumbricus terrestris. Environ. Pollut. 2017, 220, 523-531. [CrossRef]

38. Lwanga, E.H.; Thapa, B.; Yang, X.; Gertsen, H.; Salánki, T.; Geissen, V.; Garbeva, P. Decay of low-density polyethylene by bacteria extracted from earthworm's guts: A potential for soil restoration. Sci. Total Environ. 2018, 624, 753-757. [CrossRef]

39. He, D.; Luo, Y.; Lu, S.; Liu, M.; Song, Y.; Lei, L. Microplastics in soils: Analytical methods, pollution characteristics and ecological risks. TrAC Trends Anal. Chem. 2018, 109, 163-172. [CrossRef]

40. Kabasci, S. Chapter 4-Biobased plastics. In Plastic Waste and Recycling; Letcher, T.M., Ed.; Academic Press: Cambridge, MA, USA, 2020; pp. 67-96.

41. Havstad, M.R. Chapter 5-Biodegradable plastics. In Plastic Waste and Recycling; Letcher, T.M., Ed.; Academic Press: Cambridge, MA, USA, 2020; pp. 97-129.

42. Geyer, R. Chapter 2-Production, use, and fate of synthetic polymers. In Plastic Waste and Recycling; Letcher, T.M., Ed.; Academic Press: Cambridge, MA, USA, 2020; pp. 13-32.

43. Letcher, T.M. Chapter 1-Introduction to plastic waste and recycling. In Plastic Waste and Recycling; Letcher, T.M., Ed.; Academic Press: Cambridge, MA, USA, 2020; pp. 3-12.

44. Weithmann, N.; Möller, J.N.; Löder, M.G.J.; Piehl, S.; Laforsch, C.; Freitag, R. Organic fertilizer as a vehicle for the entry of microplastic into the environment. Sci. Adv. 2018, 4, eaap8060. [CrossRef] 